\title{
An invisible population-Young carers in Aotearoa New Zealand
}

Sue Hanna and Charlotte Chisnell, Eastern Institute of Technology, New Zealand

\begin{abstract}
INTRODUCTION: This paper discusses the situation of young carers, a population of children, young people and young adults who have received little attention in Aotearoa New Zealand social policy, social work practice and research.

METHOD: The authors draw attention to the status and needs of this group through a review of literature and through their reflections, as two English-registered social workers, on practice with young carers in the United Kingdom.

FINDINGS AND IMPLICATIONS: The paper argues that young carers are a vulnerable, invisible group who require recognition and respect. Using a children's rights framework, it is suggested that more attention should be given by social workers to understanding the complexity of this role, and the rights of young carers as children under the United Nations Convention on the Rights of the Child.
\end{abstract}

KEYWORDS: young carers; Aotearoa New Zealand; social work; children; caring
The term young carer "applies to children and young people under the age of age 18 who provide regular [emphasis in original] and ongoing care and emotional support to a family member who is physically or mentally disabled or misuses substances" (Research in Practice, 2016, p. 2). They are an often "hard to reach" and isolated demographic of children and young people who undertake roles within their families not undertaken by their peers (Smyth \& Michail, 2010). As a consequence, they have broader needs for support and attention in order to manage these additional responsibilities. In addition, from a statutory child protection perspective, they are vulnerable to abuse and neglect, exacerbated because the family situations in which they provide caring can be affected by addiction and mental health issues (Cunningham, Shochet, Smith, \& Wurfl, 2017;
Kennan, Fives, \& Canavan, 2012; Research in Practice, 2016).

A case study recently used as a social worker recruitment tool tells the story: Leanne is a young Māori girl, the youngest of several children. The whannau live with their extended family. Leanne complained to her teacher that she cooks dinner, cleans the house and is expected to mind her younger cousins. She arrives at school late and is often tired. The aim of the case study is to ascertain potential social work recruits' knowledge of abuse and neglect and their ability to work effectively with Māori. One of the many challenges facing Leanne, the subject of this case study, however, is that she is being used inappropriately as a young carer; she has too many responsibilities in the home for her age and stage, which she cannot manage. As the case study progresses, it becomes clear
AOTEAROA

NEW ZEALAND SOCIAL WORK 31(2), 7-17.

CORRESPONDENCE TO: Charlotte Chisnell CChisnell@eit.ac.nz 
she is suffering the consequences of this at the abusive hands of adult family members who have serious addiction issues. What exacerbates her situation is the lack of both recognition and definition of what it means to be a young carer in Aotearoa New Zealand.

In this paper, we focus on the existence and status of young carers in NZ through an exploration of relevant literature, both in Aotearoa New Zealand and the United Kingdom (UK). Reference is made to two case studies drawn from our experiences as social workers in the UK. We have predominantly cited research and literature from the UK because the needs of young carers have recently been acknowledged there, in legislation and statutory guidance. We argue that there is a growing need for researchers, social work practitioners and policy makers in Aotearoa New Zealand to do more to ensure the visibility and protect the "living rights" of this group, as young caring is a risk factor for neglect and abuse (Department for Education, 2018).

\section{Background}

Mahi Aroha Caring for Carers, the discussion document on "The proposed carers strategy action plan 2019-2023" states that there are approximately 40,000 young carers in New Zealand (Ministry of Social Development [MSD], 2019, p. 5). The same report also states that approximately $9 \%$ of carers are aged between 15 and 24 years (MSD, 2019, p. 9). Although the NZ Carers strategy (MSD, 2014) recognises young carers as a distinct group, they have not received anywhere near the levels of attention here as they have in other countries, such as the UK, Australia, Ireland and the US. To date, little research has focused on this group; one exception is McDonald, Cumming, and Dew (2009) who conducted an exploratory qualitative study with a sample of 14 young carers and nine associated family members, in which they identified the need for further research in the area. Young Carers New Zealand describe young carers as a special interest group for children and young people who help to support ill, elderly, and disabled friends and family members. Young carers often also support people who have an addiction (Supporting Families (n.d.), see supportingfamilies.org.nz).

This definition highlights that care provided by young carers is required because a family member has a chronic condition, illness, or issues with drug and alcohol addiction. The implications of this often means, however, that the young carer role is not just confined to providing medical supervision and personal care for the family member concerned, and that this may be only one aspect of the young caring role. The NZ Carers Strategy Action Plan for 2014 to 2018 (MSD, 2014) also undertook to "better understand the needs of younger carers, older carers, and carers of older people in need of assistance" (p. 24).

Much of the research attention on young carers has occurred in the UK and, from the 1980s onwards (McDonald et al., 2009; Phelps, 2017). However, this situation is acknowledged in other parts of the world and parentification is used in the US to describe this role and associated family arrangements; this is a term which captures the role reversal that occurs when children and young people assume the nature and level of caring responsibilities normally reserved for adult primary caregivers (Charles, Stainton, \& Marshall, 2009). Charles et al. (2009) make a distinction between situations where this form of role reversal happens because parents abdicate their parental responsibilities and those situations where, through necessity and family circumstances, young carers assume some, or the entire normal parental role for a temporary period (Chase, 1999, as cited in Charles et al., 2009).

The review of the literature that follows will discuss who falls into the category of a young carer, the major methodological issues associated with defining this group, its prevalence, the positive and negative 
impacts of young caring, and the statutory social work responsibilities that exist in the UK in respect of young carers.

\section{Who is a young carer?}

Definitions of young carers are contested and differ throughout the world (Cree, 2003). Ordinarily, within families, parents or adult caregivers provide care to dependent children. In the case of young carers, however, the reverse is true. In the UK, under the Children and Families Act 2014 and the Care Act 2014, a young carer is defined as a "person under 18 who provides or intends to provide care for another person" (s 63). This relates to care for any family member who is physically or mentally ill, frail, elderly, disabled, or who abuses alcohol or substances. Under the auspices of both acts, local authorities and county councils have a duty to offer an assessment where it appears a child is involved in providing care. Families, however, may choose to conceal young people's caring activities, or young carers may not define themselves as such; consequently, establishing the scope of this population has been difficult. Definitional challenges associated with establishing who young carers are, how many they number, who they care for, what forms their caring takes, how much they do and what are the impacts, have been complicated by methodological inconsistencies in the research (Aldridge, 2018). For example, definitions of young carers in several studies have used different age ranges (Cree, 2003). More recently, the term young carer has been applied more specifically to children and young people under the age 18, while young adult carers aged between 18 and 25 years have been identified as a separate and growing category (Children's Society, 2016). Additionally, while words such as regular and significant were commonly used to indicate the amount of caring undertaken, recent research has shifted the focus onto the impact of these responsibilities on children's lives (Aldridge, 2018). The locus of caring has also been extended to include caring activities that take place outside the family home (Cheesbrough, Harding, Webster, \& Taylor, 2017).

\section{What is the young caring population in the UK?}

Data from the 2011 census in the UK identified 166,363 young carers under the age of 18 years in the general population (Children's Society, 2016). Additionally, an analysis of British 2001 and 2011 census data shows a significant increase in young carers aged between 5 and 9 years of age (Children's Society, 2016). In the last four years, the number of young carers has increased by 10,000 . This situation has, arguably, transpired because of ongoing austerity cuts to adult services (Bulman, 2018).

It remains difficult to establish an accurate picture of the extent of this population of young people. Reasons for this include: the varying age ranges informing inclusion criteria in research studies (Aldridge, 2018), and observations that young carers themselves may not identify with the term, young carer (MSD, 2019); feared stigmatisation, fear of removal from their homes, parents not describing or identifying their children as carers and young carers themselves may not distinguish what they do from normal household responsibilities (Aldridge, 2018). These are all factors which contribute to the difficulties of providing an accurate picture of the size of this group.

Conflicting data about the prevalence of young carers led to completion of several studies over the last five years commissioned by the Department for Education, which utilised a range of mixed methodologies to address inconsistencies in the existing data sets (Aldridge, 2018). In 2019, research undertaken by Joseph et al. found that $22 \%$ of young people were defined as young carers with approximately $7 \%$ undertaking a high level of caring responsibility and 3\% a very high level of care. (2019, p. 2). 


\section{What do young carers do?}

Methodological issues have also affected research findings exploring what and how much young carers do. Young caring activities are currently considered as falling into six areas: domestic tasks and gardening; emotional support; intimate care (toileting, washing showering, lifting, dressing and feeding, including administration of medication); supervision of younger siblings; bill payments; and translation responsibilities for non-English-speaking relatives (Dearden \& Becker, 2004, as cited in Research in Practice, 2016). While caregiving within families is often reciprocal, and children regularly do household chores and baby-sitting, there is a continuum. Kennan et al. (2012) stress the need to differentiate between a level of caring and contribution to household tasks that is positive, and that which affects negatively of the young person's health, welfare and well-being. The point here is that children and young people should not undertake amounts of caring that would detract from their physical and emotional well-being, education or potential (The Care Act, 2014).

\section{What are the impacts, both positive and negative, of a caring role for young people?}

Young carers have acknowledged caring to be a "two-way street", with a number of positive impacts being associated with this role (McDonald et al., 2009). These include a heightened understanding of the needs of others which, in turn, contributes to increased maturity (Banks et al., 2002). The ability to provide complex caregiving tasks competently, and feeling needed, often helps young people to feel worthwhile (Aldridge \& Becker, 1993; Banks et al., 2002). The benefits of, and to, young carers of this role are acknowledged. What is identified as pivotal in distinguishing between positive and negative impacts however, is the presence of a loving parent who is reciprocally engaged and responsive to the young person and her/his needs, regardless of caring arrangements (Tatum \& Tucker, 1998). Likewise, the perceptions of the young carers themselves are also crucial. Those who feel their situation is manageable, have good social support and effective coping strategies, experience less stress and better adjustment than those who do not report these protective factors (Cunningham et al., 2017).

Most available literature, however, demonstrates clearly that the role of young carers can have negative impacts on young people's self-esteem, their social relationships, educational attainment and transition into adulthood (Children's Society, 2013, 2016; Cree, 2003; Dearden \& Becker, 2004; Moore, McArthur, \& Morrow, 2009). In the UK, for example, $27 \%$ of young carers miss school or experience educational difficulties. This compounds significantly when caring for relatives with drug or alcohol misuse problems. Young carers are 1.5 times more likely to have a special educational need or disability. As a group, they achieve significantly lower educational attainment at General Certificate in Secondary Education (GCSE), the equivalent of nine grades lower than their peers do, and are less likely to go on to higher or further education. They are more likely not to be in education, employment and training between the ages of 16-19 (Children's Society, 2013, 2016; Dearden \& Becker, 2004). According to the 2011 British Census, young carers are twice as likely to report "not good health". This increased to five times as likely when involved in caring for over 50 hours per week. Young carers have acknowledged the stress associated with the role and a school survey found that $38 \%$ of young carers had mental health problems (Children's Society, 2013).

The length of time spent caring, the nature and severity of the family member's illness, incapacity or disability (Cree, 2003), the age of the young carer (Dearden \& Becker 2004), and the amount of responsibility for caregiving (Children's Society, 2016) all impact on the well-being, education and 
emotional development of young carers. In addition, these impacts are affected by the level of informal and formal support available outside the home (Children's Society, 2016), and physical conditions and levels of support for the young carers within the home.

\section{Protective factors and the development of resilience}

The risk factors associated with the role of young caring can contribute to the child experiencing the adverse conditions of social exclusion and neglect. However, research suggests that there are a number of protective factors that support children and which help them develop resilience. Resilience can enable a child to grow and develop despite facing adverse circumstances. It is associated with the presence of a combination of protective factors including psychological attributes, family support, and external support systems. "Resilient children are better equipped to resist stress and adversity, cope with change and uncertainty, and to recover faster and more completely from traumatic events or episodes" (Newman \& Blackburn, 2002, p. 1). For example, a study of young carers in Northern Ireland found that appropriate knowledge of their parent's illness had a positive impact on the child's capacity for resilience (McGibbon, Spratt, \& Davidson, 2018).

\section{Factors contributing to young caring}

How do children and young people find themselves in these roles? The major determining factors contributing to young caring involve poverty and low income, factors in the UK exacerbated by policies of fiscal austerity, with resulting negative impacts on welfare and the provision of social services (Aldridge, 2018). Lone parenthood is also being identified as a contributing factor (Aldridge, 2018). The Children's Society report Hidden from View (2013) identifies that young carers are also one-and-a-half times more likely to come from black or ethnic minority communities, and twice as likely to speak English as a second language. Increasingly, research has identified that, in 29\% of circumstances, young carers are assuming caring responsibilities in homes where adults have mental health issues and problems with addictions (Children's Society, 2016).

\section{Statutory responses to young carers}

Identifying young carers, however, is not necessarily straightforward. In England and Wales, social workers have a statutory duty of care under the Care Act 2014 and the Children and Families Act 2014, to recognise and undertake assessments when young people are involved in caring. As noted, there are many reasons why young carers are a hidden population, and families often conceal young carers' roles because of the common fear that statutory social work intervention may result in family separation. Care figures justify this fear, with more than 2000 children placed in state care because of the parent's illness or disability. The number of children placed in care through "parental illness or disability" ranged between 2,380 and 2,720 annually (2011-2015), which represented $3-4 \%$ of all children placed in care (Zayed \& Harker, 2015). Research undertaken in England to establish how effective the legislative changes had been in improving the identification and support of young carers and their families found support for young carers varied considerably. Only $19 \%$ of parents of young carers reported that their child had received an assessment of their needs by the local authority; the main support they received came from young carer projects or schools, and $64 \%$ received no support at all (Cheesbrough et al., 2017).

The following case studies highlight some of the tensions and dilemmas that arise when working with young carers. 


\section{First case study}

During the second author's practice as a social worker within statutory children's services in the UK, there was the opportunity to work with children and their families within a number of different settings. Throughout this time, I witnessed how easily children and young people assume the role of carer, usually without complaint.

There may be a variety of different reasons, which can lead to parentification, or the reversal of roles within families, but this case study focuses on two specific areas of practice; these are: working with parental substance misuse, and mental health issues.

While there may be increased risks associated with children living with parental substance misuse or parental mental health issues, there are not always safeguarding concerns or difficulties in parenting capacity (Davies \& Ward, 2011; Velleman \& Templeton, 2016). The harm, which remains hidden, is the harm which occurs when children and young people assume the role of carer without support or recognition. During practice as a child and family social worker, I observed how children and young people who are in this situation often lack routine and live chaotic lives.

Children in this situation are likely to experience a poor diet, and to miss school and health appointments. Despite the impact that caring responsibilities can have on children and young people, many young carers are very loyal to their parents, and often reluctant to disclose the full extent of their responsibilities in case they are removed from the family home (Sempik \& Becker, 2014).

Unfortunately, my contact with young carers often came when the child/young person transitioned from a child in need to being a child at risk of significant harm. One of the most traumatic cases I experienced concerned a mother and her two children aged 5 and 7 years.
The seven-year-old was a young carer. The case only reached the attention of local Child and Family services following a house fire in which the family was involved.

For a number of years, the mother had been able to manage her alcohol dependency, her paid work and the care of her children. Unfortunately, when she lost her job. her alcohol dependency became more acute and she found it difficult to provide care for them. The situation continued to deteriorate and concerns were noted by the children's school, because their appearance was sometimes dishevelled and they appeared to have lost weight, however no action was taken and no referrals were made to the local authority statutory Child and Family Services. The situation was not judged to present as a risk to the two children.

The elder child, a boy, was fiercely devoted to his mother and had promised her he would not tell anyone about their situation because he had been told that, if he did, he and his sister would be "taken away". He provided physical and emotional care for both his mother and his sister. He washed clothes, helped his younger sister to dress, cooked meals and cleaned. On one occasion, whilst he was cooking baked beans, a dishtowel caught fire, which ignited the curtains in the kitchen. The boy managed to pull both his mother and his sister out of the flat before the fire brigade arrived.

Consequently, the children were moved into foster care because of concerns they were being neglected and an assessment of potential further risk of significant harm was undertaken. However, despite reassurance, the boy believed that he had failed his mother and that it was his fault that he and his sister were placed in state care.

Unfortunately, there is a popular view that mental health issues and substance 
misuse are personal and moral failings rather than being social and health issues that require support and treatment. Within this context, parents who misuse drugs or alcohol are often judged as irresponsible or failing parents (Manning, Best, Faulkner, \& Titherington, 2009). This negative and oppressive view can have the effect of reducing both the parents' and the children's willingness to seek and engage with support, as the above case exemplifies, consequently this presents a significant barrier to valuable early engagement with support services.

Reflecting on the social work practice lessons from this particular case, there appear to be two major ones. First, the extent to which adult and children's services work effectively together to assess concerns and support families varies considerably. This lack of communication can exacerbate the isolation that young carers experience. The importance of effective, multi-agency working where children are vulnerable or at risk has been consistently highlighted by the Working Together statutory guidance (Department for Education, 2018).

Second, young carers are often resilient and usually want to continue with their caring responsibilities because they do not want to disrupt the family or risk being placed in state care. Our priority as social workers should be to provide the type of support which serves to strengthen children's resilience. Within this context, one key aspect of the social work process should be to listen to what children and young people are saying and involve them in professional discussions about their own care and that of their parent(s) and siblings. McGibbon et al. (2018) undertook a qualitative piece of research examining the experiences of 22 young carers in Northern Ireland. The aim of the study was to identify factors which could both challenge or develop young carers' resilience. The results demonstrated that providing young carers with knowledge about their parent's illness and involving them in care-planning discussions had a positive impact on their resilience.
Historically, professionals have been criticised for their lack of focus on the child, making the child almost invisible (Munro, 2011). Bee, Berzins, Calam, Pryjmachuk, and Abel (2013) suggest that professionals can fail to take into consideration the views of children, and fail to share information with them about what is happening to their parents. A further risk in my experience is that professionals may focus more attention on the needs and views of the parent, and not fully consider the child's perspective.

\section{Second case study}

This second case study, also from the UK and provided by the lead author, offers an example of what can be accomplished with young carers when interventions can be planned, and when the rights of children under Article 12 of the United Nations Convention On the Rights of Children are respected, and their voices are heard and acted upon.

During my time working for a London based local authority, I had the opportunity to co-work a case involving a young adult carer, with social workers employed in statutory child protection services in a Family Support and Protection team, which had responsibility for managing longer-term interventions with families.

It began as an urgent referral about spousal domestic abuse, involving a mother of four children. There was a history of domestic violence in the relationship, however, on this occasion the attack resulted in the mother being hospitalised because of her injuries. At that point, she terminated the relationship with her husband and brought charges against him, for which he was sentenced to a term of imprisonment. Sadly, the mother was diagnosed with a serious illness and subsequently died. Prior to her death, a lot of careful work was done with the children to ascertain their wishes about their future. They wanted four things, to 
remain together as a sibling group, and for the eldest sibling to be their caregiver, to have no contact with their father, and finally to stay in their family home, (a local housing association flat). The eldest child was 18, legally an adult in the UK, the youngest child was eight, and there were two children between these two ages. The social worker involved was committed to hearing the voices of children in this family, to putting them at the heart of the social work process and to ensuring they had the support they needed to become an independent family unit in the care of their eldest sibling. It was what the children wanted, but it was obviously a considerable responsibility and commitment for the eldest sister to assume at her age and her stage.

The children were able to access wraparound support services for their newly constituted family that ensured that the children's schools were aware of their situation, and that the eldest sibling was able to pursue study; they accessed ongoing family and individual counselling, and had sufficient financial support.

At the time of my involvement, legal orders were in the process of being finalised. In a family meeting I attended, the social worker carefully outlined the impending court processes required to finalise the legal guardianship and custody orders. The social worker then met with each of the children individually, including the eldest sibling. Something that struck me, as the youngest child showed me around their home, was the large notice board in the kitchen covered in messages about the children's individual achievements, and group notes to self about what they were proud of about their family. This was a visual demonstration of their collective identity as a functional, competent, successful, hopeful family. The social worker had formed a strong bond with each of the children, strong enough for the youngest girl to confide how much she still missed her mother, and be comforted by his response.

Albeit that the time frames were different for both the cases cited, this example has been included to demonstrate how well it is possible to support young carers when interventions can be planned, focussed, prioritise the voices of children, and address the challenges of their daily lives in a holistic way.

\section{Discussion}

It is usual for children to contribute to the smooth running of a household by undertaking some cleaning, and or cooking and supervision of younger siblings. In fact, these chores are often encouraged and considered developmentally desirable. These expectations become problematic, as noted, however, when the caring responsibilities and tasks required of children and young people are excessive or inappropriate for the child's age and stage, and negatively impact their education, well-being, social networks, and life opportunities.

Recent literature and practitioner experience suggests strongly that, when working with young carers and their families, it is important to respect and achieve a balance between a duty of care toward young carers, whilst respecting their contribution to family life and acknowledging family relationships are reciprocal and interdependent (Phelps, 2017; Research in Practice, 2016). This is, as the first case demonstrates, a delicate balance to maintain.

Worldwide, social work interventions for young carers are generally limited (Cunningham et al., 2017). Although social workers in the UK have a statutory duty of care under the Care Act 2014 and the Children and Families Act 2014 to assess the situation of young carers, mechanisms for screening and assessing the needs of young carers vary in quality, are inconsistent, or do not exist (Aldridge, 2018). In addition, 
despite the implementation of appropriate legislation, progress toward realising the legal requirement to offer assessments to young carers remains very slow (Cheesbrough et al., 2017). There are a number of reasons for this. The most obvious is the broader systemic impact of austerity on contracting social care budgets, and a refocusing of funds away from prevention and early intervention towards risk management.

The lack of progress on attention to young carers may also be related to the way this group of children and young people are positioned in the child-protection discourse. Young carers are often a silent, takenfor-granted, population. They are largely invisible, do not complain and, when identified, are usually seen as being "in need" rather than "at risk",' i.e., children who require support as opposed to children who are at risk of significant harm. They perform an important social function keeping families together and often do not seek recognition. The first case that was reported on demonstrates what happens to young carers when their situation becomes an emergency that requires urgent involvement with statutory child and family services. At this point, as was evidenced, the state takes over, and young carers may not be involved in the decisions made in respect to their future. They manage unrealistic expectations and responsibilities as best they can until it becomes too much for them and then, to place a further burden on them, circumstances are taken out of their control as though their former contribution was meaningless.

This paper seeks to challenge the low visibility, and lack of recognition young carers experience in Aotearoa New Zealand. This group is recognised in the UK, and has received attention from researchers and charitable organisations since the 1980s. Why is it that a legal duty of care toward young carers is enshrined in two major pieces of UK legislation, but they receive so little attention in Aotearoa New Zealand? Why, we ask ourselves, do the most recent figures from the UK estimate that there are 166,363 young people identified as young carers (Cheesbrough et al., 2017; Phelps, 2017), and no statistical recognition of this group of young people in Aotearoa New Zealand? This may have something to do with attitudes towards personalised informal care which is the norm for many families, or how children's informal care work is socially constructed in Aotearoa New Zealand (McDonald et al., 2009). One possibility is that caring work done by children is minimised and reframed as normal: "a little bit of house work never hurts anyone, it didn't do me any harm." It may well be that the combination of these factors contributes to the invisibility and invalidation of young carers' experiences. In Aotearoa New Zealand, we argue, if the current social construction of young carers continues to be accepted as a norm within families, rather than acknowledged as an issue, the long-term potential exploitation of this group's labour and domestic servitude will continue.

Aotearoa New Zealand is a signatory to the 1989 United Nations Convention on the Rights of the Child (UNCROC) (United Nations, 1989). Article 12 (1) of this convention places an obligation for agencies to involve children in decisions that affect them. The rights of children, however, to have a voice in respect of their own selfdetermination, and the processes affecting their lives, have been deemed controversial (Smith, 2016). The right to participate alters the perception of a child from being a passive recipient of adults' actions, to one that sees children as separate social actors-people in their own right (Smith, 2016). Apropos of this, Phelps (2017) suggests the voice of the young child needs to be heard and "filtered through the prism of professional understanding based on legislation and the rights of the child" (p. 118).

However, before these rights can be upheld, the group's status needs to be acknowledged. The recognition of children as social actors, rights' holders, and as having living rights 
will assist with many of the social work practice challenges identified in naming and subsequently working respectfully with young carers and their families. The concept of children and young people as social actors views children and young people as active in the construction of their own lives not just as the objects of adult concern, but able to exercise self-determination and articulate independent viewpoints in their own right. Smith (2016) comments that children are rights' holders and this involves recognising that, as such, they should be empowered to make claims and hold to account, social workers and families, who are recognised as primary and secondary duty bearers, for protecting the rights of all children. Associated with this, the idea of living rights incorporates the need for children's rights to exist beyond policies and legislation as meaningfully contextualised within their daily lives so as to make a make a real and discernible difference. Leanne's situation, for example, as referenced at the beginning of this article, is unlikely to enable her to get a tertiary education qualification. For this to happen, young carers need the backing of social workers, as primary duty holders, to support them to have a voice, as well as the opportunity to use it, to make their living rights meaningful (Smith, 2016). The participation of young carers is essential to gain insight into this unique role and the variety of family circumstances that necessitate it and thus enabling the development of an appropriate social policy context to support practice with this group (Phelps, 2017).

\section{Conclusion}

Aotearoa New Zealand is a signatory to the UNCRC and, according to Article 12, the state has a responsibility to guarantee that all children have a voice, to recognise that they are capable of forming their own views, have the right to express their views and have them taken seriously. This paper argues that young carers are a hard-to-reach and potentially vulnerable population of children and young people in Aotearoa
New Zealand who, as an identifiable group, do not get due recognition and attention from social workers as primary duty holders. Their lack of visibility is concerning, given what overseas research and practice suggests about the challenges facing this group, and what is already known about the support they often need to ensure their own needs are not sacrificed for the needs of those for whom they are caring.

As a profession, we owe it to this group of children, young people and young adults to do better by them. A good start would be to recognise their unique status, and to establish with them what they need.

\section{References}

Aldridge, J. (2018). Where are we now? Twenty-five years of research, policy and practice on young carers. Critical Social Policy, 38(1), 155-165. doi. org/10/1177/0261018317724525

Aldridge, J., \& Becker, S. (1993). Punishing children for caring: The hidden cost of young carers. Children \& Society, 7(4), 376-387. doi:10.1111/j.1099-0860.1993. tb00293.x

Banks, P., Cogan, N., Riddell, S., Deeley, S., Hill, M., \& Tisdall, K. (2002). Does the covert nature of caring prohibit the development of effective services for young carers? British Journal of Guidance and Counselling, 30(3), 229-246. doi.org/10.1080/030698802100002281

Bee, P., Berzins, K., Calam, R., Pryjmachuk, S., \& Abel, K. M. (2013). Defining quality of life in the children of parents with severe mental illness: A preliminary stakeholder-led model. PLoS ONE, 8(9), e73739. doi:10.1371/journal. pone.0073739

Bulman, M. (2018, January 28). Number of young carers in UK soars by 10,000 in four years, figures show. Independent. Retrieved from https://www.independent. co.uk/news/uk/home-news/young-carers-uk-numbersrise-figures-support-family-social-care-benefitscommunity-a8177806.html

Charles, G., Stainton, T., \& Marshall, S. (2009). Young carers: Mature before their time. Reclaiming Children \& Youth, 18(2), 39-41.

Cheesbrough, S., Harding, C., Webster, H., \& Taylor, L. (with Arlidge, J.). (2017). The lives of young carers in England: Omnibus survey report, January 2017. Retrieved from https://assets.publishing.service.gov.uk/ government/uploads/system/uploads/attachment_data/ file/582575/Lives_of_young_carers_in_England_ Omnibus_research_report.pdf

Children's Society. (2013). Hidden from view. London, UK: Author.

Children's Society. (2016). Supporting young carers and their families. London. UK: Author.

Cree, V. E. (2003). Worries and problems of young carers: Issues for mental health. Child \& Family Social Work, 8(4), 301-309. doi.org/10.1046/j.1365-2206.2003.00292. 
Cunningham, L., Shochet, I., Smith, C., \& Wurfl, A. (2017). A qualitative evaluation of an innovative resiliencebuilding camp for young carers. Child \& Family Social Work, 22, 700-710.

Davies, C., \& Ward, H. (2011). Safeguarding children across services: Messages from research. London, England: Jessica Kingsley Publishers.

Dearden, C., \& Becker, S. (2004). Young carers in the UK: The 2004 report. London, UK: Carers UK.

Department for Education. (2018). Working together to safeguard children: A guide to inter-agency working to safeguard and promote the welfare of children. Retrieved from https://www.gov.uk/government/publications/ working-together-to-safeguard-children--2

Joseph, S., Kendall, C., Toher, D., Sempik, J., Holland, J. \& Becker, S. (2019). Young carers in England: Findings from the 2018 BBC survey on the prevalence and nature of caring among young people. Child: care, health and development, 45(4), 606-612.

Kennan, D., Fives, A., \& Canavan, J. (2012). Accessing a hard to reach population: Reflections on research with young carers in Ireland. Child and Family Social Work, 17, 275-282. doi:org//10.1111/j.1365-2206.2011.00778.x

Manning, V., Best, D. W., Faulkner, N., \& Titherington, E. (2009). New estimates of the number of children living with substance misusing parents: Results from UK national household surveys. BMC Public Health, 9(377), 1-12. doi:10/1186/1471-2458-9-377

McDonald, J., Cumming, J., \& Dew, K. (2009). An exploratory study of young carers and their families in NZ. Kotuitui: NZ Journal of Social Service Online, 4(2), 115-129. doi: 10.1080/1177083X.2009.9522448

McGibbon, M., Spratt, T., \& Davidson, G. (2018). Young carers in Northern Ireland: Perceptions of and responses to illness and disability within the family. British Journal of Social Work. https://doi.org/10.1093/bjsw/bcy102

Ministry of Social Development. (2014). The New Zealand carers' strategy action plan. Wellington, New Zealand: Author.

Ministry of Social Development. (2019). Mahi Aroha Caring for Carers the discussion document on the proposed carers strategy action plan 2019-2023. Wellington, NZ: Author.

Moore, T., McArthur, M., \& Morrow, R. (2009). Attendance, achievement and participation: Young carers' experiences of school in Australia. Australian Journal of Education, 53(1), 5-18.

Munro, E. (2011). The Munro review of child protection: Final report: A child-centred system. London, England: Department for Education.

Newman, T., \& Blackburn, S. (2002). Transitions in the lives of children and young people: Resilience factors. Edinburgh, Scotland: Scottish Executive Education Department.

Phelps, D. (2017). The voices of young carers in policy and practice. Social Inclusion, 5(3), 113-121. doi. org/10.17645/si.v5i3.965

Research in Practice. (2016). Young carers and their families: Confident assessment practice. Totnes, United Kingdom: Author.

Sempik, J., \& Becker, S. (2014). Young adult carers at college and university. London, England: Carers Trust.
Smith, A. B. (2016). Children's rights: Towards social justice. New York, NY: Momentum Press.

Smyth, C., \& Michail, S. (2010). Exploring young carers' agency. Qualitative Research Journal, 10(2), 36-50. doi. org/10/3316/QRJ1002036

Tatum, C., \& Tucker, S. (1998). The concealed consequences of caring: An examination of the experiences of young carers in the community. Youth and Policy, 61, 12-27.

The Care Act. (2014). Retrieved from www.legislation.gov.uk

The Children and Families Act. (2014). Retrieved from www.legislation.gov.uk

United Nations. (1989). Convention on the Rights of the Child. Retrieved from https://www.unicef.org/child-rightsconvention

Velleman, R., \& Templeton, L. J. (2016). The impact of parents' substance misuse on children: An update. British Journal of Psychiatry Advances, 22(2), 108-117. doi.org/10.1192/apt.bp.114.014449

Supporting Families. (n.d.). Retrieved from https:// supportingfamilies.org.nz/young-carers/

Zayed, Y., \& Harker, R. (2015). Children in care in England: Statistics (Briefing paper 04470). London, England: House of Commons Library. 